\title{
Transcriptional Activator MN1
}

National Cancer Institute

\section{Source}

National Cancer Institute. Transcriptional Activator MN1. NCI Thesaurus. Code C97620.

Transcriptional activator MN1 (1320 aa, $136 \mathrm{kDa}$ ) is encoded by the human MN1 gene.

This protein plays a role in transcriptional activation druing palate development, osteoblast activity and skull development. 